\title{
MINIMUM-WEIGHT DESIGN \\ OF COMPRESSIVELY LOADED COMPOSITE PLATES \\ AND STIFFENED PANELS \\ FOR POSTBUCKLING STRENGTH \\ BY GENETIC ALGORITHM
}

\author{
Ji-Ho Kang ${ }^{\mathrm{a}}$, Jae-Hun Lee ${ }^{\mathrm{a}}$, Joo-Hyun Han ${ }^{\mathrm{a}}$, Chun-Gon Kim ${ }^{\mathrm{a}}$, and Dong-Min Lee ${ }^{\mathrm{b}}$ \\ ${ }^{a}$ Division of Aerospace Engineering, Department of Mechanical Engineering \\ Korea Advanced Institute of Science and Technology \\ 373-1, Kuseong-dong, Yuseong-gu, Daejeon, 305-701, Korea \\ ${ }^{b}$ Agency of Defense Development, Yuseong P. O. Box 35, Daejeon, Korea
}

\begin{abstract}
SUMMARY: The minimum-weight design of compressively loaded laminated plates and stiffened panels was aimed under constrained postbuckling strength in this paper. A nonlinear finite element code, COSAP(COmposite Structure Analysis Program) was applied to analyze the precise buckling and postbuckling behaviour. As an optimization technique, Genetic Algorithm was used to find the optimum points in the design space. A conventional genetic algorithm was modified with two new techniques. One is the use of the pre-calculated result to reduce the calculation cost, and the other is the use of variable population size in genetic algorithm to find better optimum points. The modified Genetic Algorithm code was then parallelized with MPI(Message Passing Interface) library and the optimization was executed with a parallel-computing supercomputer, CRAY T3E. The optimal design was performed in two cases; a composite plate and a composite stiffened panel. The design variables were number of plies and the ply angle in each ply. In case of the stiffened panels, the size and spacing of the stiffeners were also considered as the design variables. The objective function was defined as the product of the nondimensional weight and strength. The optimization was performed with two chosen examples, and the results showed that the optimal designs have better performances than conventional designs.
\end{abstract}

KEYWORDS: weight-minimization, optimal design, genetic algorithm, composite, postbuckling

\section{INTRODUCTION}

Fiber reinforced composite materials have superior characteristics as the variable stacking sequences 
and ply angles when compared to conventional materials. Therefore optimal design can be achieved by determining the proper stacking sequences and ply angles. However, there are some difficulties in optimal design like discreteness of the design values and complexity of the design spaces. In 1990's, many researches using discrete ply angles as design variables were conducted[1-5]. In the previous researches, it is inevitable to use discrete ply angles such as $0^{\circ}, 90^{\circ}$, or $\pm 45^{\circ}$ for designing realistic composite structures. Weight and manufacturing efficiency as well as stiffness or strength were considered. Furthermore the number of plies and the shapes should be optimized to reduce weight, and some researchers considered them. One more important issue is considering postbuckling behavior. Buckling of aerospace structures does not mean whole structural collapse and it is reasonable to design structures allowing buckling of skins[1,5]. In this paper, the minimum-weight design of compressively loaded laminated plates and stiffened panels was performed using a nonlinear finite element code and a modified genetic algorithm with parallel computing scheme.

\section{NONLINEAR FINITE ELEMENT ANALYSIS FOR COMPOSITE STRUCTURES}

A nonlinear finite element analysis code for composite structures, COSAP(COmposite Structure Analysis Program) which was developed in the papers[6-8], was used to analyze buckling and postbuckling behavior of composite plates and stiffened panels in this study. A brief formulation procedure of the analysis is stated below.

At an arbitrary $(n+1)$ th equilibrium state, the principle of virtual work without body force terms can be rewritten in terms of the second Piola-Kirchhoff stress, $S_{i j}$ and the Green strain, $\varepsilon_{i j}$ with taking the configuration at the $n$th equilibrium state as the reference one:

$$
\iiint_{V^{n}}\left(\sigma_{i j}^{n}+\Delta S_{i j}\right) \delta\left(\Delta \varepsilon_{i j}\right) d V-\iint_{S_{T}^{n}}\left(T_{i}^{n}+\Delta T_{i}\right) \delta\left(\Delta u_{i}\right) d S=0
$$

where $\sigma_{\mathrm{ij}}, \mathrm{e}_{\mathrm{ij}}, \mathrm{T}_{\mathrm{i}}, \mathrm{u}_{\mathrm{i}}$, and $\delta$ are the Cauchy stress, infinitesimal strain, surface traction, displacement, and variation operator respectively.

The Green strain, $\Delta \varepsilon_{\mathrm{ij}}$ can be divided into the linear term, $\Delta \mathrm{e}_{\mathrm{ij}}$ and nonlinear term, $\Delta \mathrm{n}_{\mathrm{ij}}$.

$$
\Delta \varepsilon_{i j}=\Delta e_{i j}+\Delta \eta_{i j}
$$

By substituting $\Delta \varepsilon_{\mathrm{ij}}$ given in eqn (2) to eqn (1), eliminating second-order terms, and implementing stress-strain relation, the equation can be obtained as 


$$
\begin{aligned}
& \iiint_{V^{n}} \delta\left(\Delta e_{i j}\right) D_{i j k l}^{n} \Delta e_{k l} d V+\iiint_{V^{n}} \sigma_{i j}^{n} \delta\left(\Delta u_{k, i}\right) \Delta u_{k, j} d V \\
& =\iint_{S_{T}^{n}}\left(T_{i}^{n}+\Delta T_{i}\right) \delta\left(\Delta u_{i}\right) d S-\iiint_{V^{n}} \sigma_{i j}^{n} \delta\left(\Delta e_{i j}\right) d V
\end{aligned}
$$

where $D_{\mathrm{ijkl}}$ is the stress-strain relation matrix in he global coordinate system.

The degenerated shell element with 8-nodes is used for the formulation. Each node has 5 DOF's and the shear deformation was considered from the first-order shear deformation theory. The strain and the displacement can be expressed with the shape functions of the element and the nodal DOF vector.

$$
\{\Delta e\}=\left[B_{L}^{n}\right]\left\{\Delta U_{n}\right\},\left\{\Delta u_{, k}\right\}=\left[B_{N L}^{n}\right]\left\{\Delta U_{n}\right\}
$$

The finite element equation can be obtained by putting eqn (4) to eqn (3) as

$$
\left(\left[K_{L}\right]+\left[K_{N L}\right]\right)\left\{\Delta U_{n}\right\}=-\{\Delta P\}
$$

where

$$
\begin{aligned}
& {\left[K_{L}\right]=\iiint_{V^{n}}\left[B_{L}^{n}\right]^{T}\left[D^{n}\right]\left[B_{L}^{n}\right] d V} \\
& {\left[K_{N L}\right]=\iiint_{V^{n}}\left[B_{N L}^{n}\right]^{T}\left[\bar{\sigma}^{n}\right]\left[B_{N L}^{n}\right] d V} \\
& \{\Delta P\}=\iiint_{V^{n}}\left[B_{L}^{n}\right]^{T}\left\{\sigma^{n}\right\} d V-\left\{F_{n}\right\}
\end{aligned}
$$

In the previous eqns, $\{\mathrm{Fn}\}$ is the nodal force vector and $\{\sigma\},[\sigma]$, and $[\bar{\sigma}]$ are defined as follows.

$$
\begin{aligned}
& \{\sigma\}=\left[\begin{array}{llllll}
\sigma_{x} & \sigma_{y} & \sigma_{z} & \tau_{y z} & \tau_{x z} & \tau_{x y}
\end{array}\right]^{T} \\
& {[\sigma]=\left[\begin{array}{lll}
\sigma_{x} & \tau_{x y} & \tau_{x z} \\
\tau_{x y} & \sigma_{y} & \tau_{y z} \\
\tau_{x z} & \tau_{y z} & \sigma_{z}
\end{array}\right]} \\
& {[\bar{\sigma}]=\left[\begin{array}{ccc}
{[\sigma]} & 0 & 0 \\
0 & {[\sigma]} & 0 \\
0 & 0 & {[\sigma]}
\end{array}\right]}
\end{aligned}
$$


In the iteration process of the finite element equation, the arc-length method was used in the loadincrement. To estimate the failure load of the structures, the maximum stress criterion is applied to the average stresses in the principal material directions of each layer in each element. The stress component corresponding to the failure mode is unloaded instantaneously. The postbuckling strength is assumed to be the load at the moment of the first fiber failure.

\section{GENETIC ALGORITHM}

Genetic algorithm[7] was used as the optimization method in this study. It simulates the natural evolution so that multiple design points evolve to be converged to a global optimum. Its calculation process uses nondeterministic scheme and has nothing to do with differentiability or convexity. The most useful advantage is that it uses discrete design variables by nature; therefore, it is simple to use the discrete ply angles of composites as design variables.

\section{Parallel Computing Technique}

Genetic algorithm is the one that is very suitable for parallel computing scheme because multiple design points should be evaluated in a calculation step. In other words, the algorithm can be programmed so that multiple design points in a generation may be divided into some sub-population and one processor in a parallel computer calculates one sub-population respectively. The programming was done with MPI(Message Passing Interface) library in this study. Its schematic diagram is shown in Fig. 1. The computing system used was CRAY-T3E in the KISTI Supercomputing Center in Korea and 16 processors of the system were implemented in this study.

\section{Modification of Genetic Algorithm for Acceleration}

In Genetic algorithm process, the fitness of the whole population should be evaluated for each generation. However, population aggregates to an optimum as convergence is accomplished and some design points that are same to the ones in the previous generation are re-evaluated, which means the waste of computing resources and time. Therefore, it is necessary to avoid the waste by modifying the algorithm. There can be many kinds of modifications possible but we implemented our own idea to solve the problem. The procedure can be explained briefly as follows:

1. Write all the fitness evaluation results into a file.

2. Make new generation considering the fitness of the population.

3. In the new generation, find out which design point is same to the previous one that is in the written file. 
4. Read the written results from the file for the overlapped design points that are found in Step 2.

5. Do the real evaluation for newly generated design points only.

6. Append the fitness evaluation results in Step 3 to the file.

7. Go to Step 2 and repeat the procedure.

This method dramatically reduces the number of the real evaluation of fitness values. However, the finding process(step 3) might be a time-consuming work, so the method should be applied carefully. In this study, we used the nonlinear finite element analysis for the fitness evaluation. The time consumption of the fitness evaluation is enormous and cannot be compared with the method stated above. Therefore, we decided to apply this method and modify the Genetic Algorithm. One more thing was implemented in the modification, the variable population size. The population size automatically increases in order to guarantee that the minimum of the number of the real evaluation of fitness is equal to or greater than a particular number which the designer designates. The utility of the variable population size makes the algorithm robust even in the case where the initial population size is relatively small and too early convergence is induced, which is undesirable.

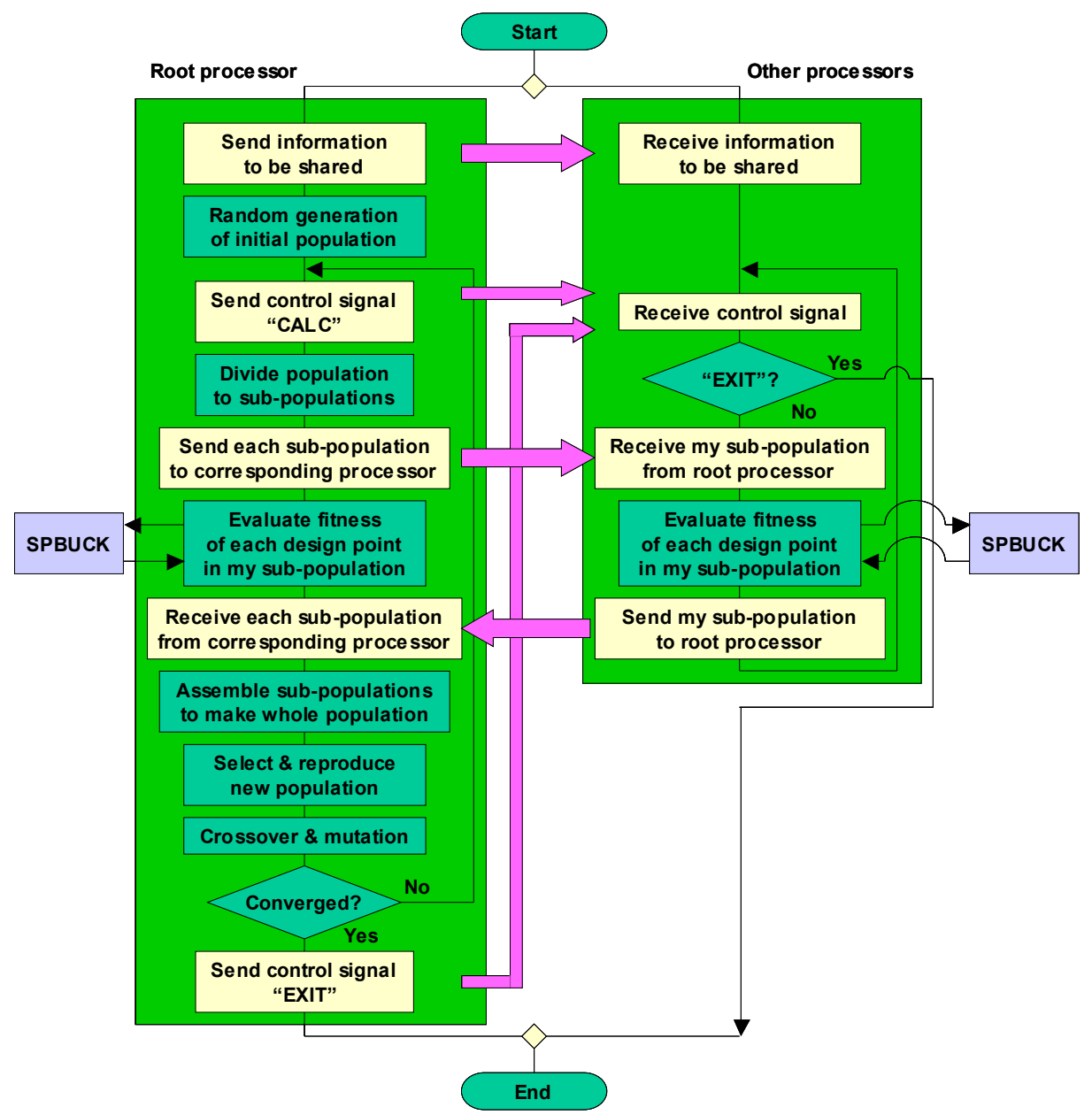

Fig. 1. Schematic diagram of Genetic Algorithm with parallel computing. 


\section{OPTIMAL DESIGN OF COMPOSITE PLATES AND STIFFENED PANELS}

\section{Problem Definition}

The optimal shapes, stacking sequences, and ply angles were searched for some composite structures with the modified Genetic Algorithm stated above. The objective of the optimization was to find the minimum weights of the structures that resist design strength. The objective function was defined as:

$$
f=\left\{\begin{array}{ccc}
\frac{W_{\max }}{W} \frac{11 P_{\text {fail }}}{10 N_{c r}+P_{\text {fail }, \text { design }}} & , \quad P_{\text {fail }} \geq P_{\text {fail design }} \\
\frac{P_{\text {fail }}}{P_{\text {fail,design }}} & , \quad P_{\text {fail }}<P_{\text {fail,design }}
\end{array}\right.
$$

where $W_{\max }$ is the possible heaviest weight and $W$ is the weight of the design point. $P_{\text {fail,design }}$ and $P_{\text {fail }}$ are the design strength and the strength of the design point respectively.

\section{Optimal Design of Composite Plates}

The shape of the plate, the boundary conditions, and the loading conditions are shown in Fig. 2. The possible maximum numbers of plies was set to 16 and only 8 plies were used as design variables because all laminates were assumed to be symmetric. The usable ply angles were set to $0^{\circ}, \pm 45^{\circ}, 90^{\circ}$ for practical application. The material properties of the composite material are shown in Table 1. The design strength was fixed $30 \mathrm{kN}$ in this example.

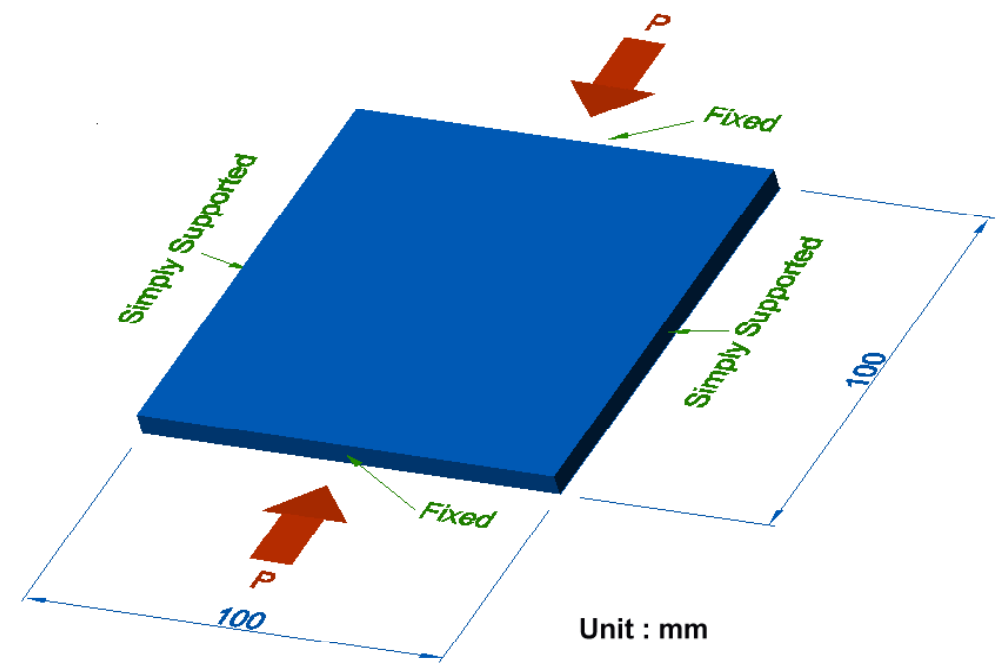

Fig. 2. The shape, the boundary conditions, and the loading conditions of composite plate. 
Table 1. The material properties of the composite material

\begin{tabular}{c|c|c|c}
\hline \hline property & value & property & value \\
\hline $\mathrm{E}_{1}$ & $130.0 \mathrm{GPa}$ & $v_{12}$ & 0.31 \\
$\mathrm{E}_{2}$ & $10.0 \mathrm{GPa}$ & $v_{13}$ & 0.31 \\
$\mathrm{E}_{3}$ & $10.0 \mathrm{GPa}$ & $v_{23}$ & 0.52 \\
$\mathrm{G}_{12}$ & $4.85 \mathrm{GPa}$ & $v_{21}$ & 0.024 \\
$\mathrm{G}_{13}$ & $4.85 \mathrm{GPa}$ & $v_{31}$ & 0.52 \\
$\mathrm{G}_{23}$ & $3.62 \mathrm{GPa}$ & $\mathrm{v}_{32}$ & 0.024 \\
$\mathrm{X}_{\mathrm{T}}$ & $1933 \mathrm{Mpa}$ & $\mathrm{Y}_{\mathrm{T}}$ & $51 \mathrm{Mpa}$ \\
$\mathrm{X}_{\mathrm{C}}$ & $1051 \mathrm{MPa}$ & $\mathrm{Y}_{\mathrm{C}}$ & $141 \mathrm{MPa}$ \\
$\mathrm{S}$ & $61 \mathrm{MPa}$ & ply thickness & $0.125 \mathrm{~mm}$ \\
\hline \hline
\end{tabular}

The optimization result showed that the optimal staking sequence and ply angles were $\left[0 / 90 / 0_{2} / 90\right]_{\mathrm{s}}$. The optimized plate has the strength of $34.9 \mathrm{kN}$ which is $16 \%$ greater than the design value and is $37.5 \%$ lighter than the possible heaviest plate. Fig. 3 shows the load-deflection curves of three different plates of same weight; the optimized plate, a quasi-isotropic plate with $[0 / \pm 36 / \pm 72]_{\mathrm{S}}$, and a unidirectional plate with $\left[0_{10}\right]_{\mathrm{T}}$. It shows that only the optimized plate resists the design strength.

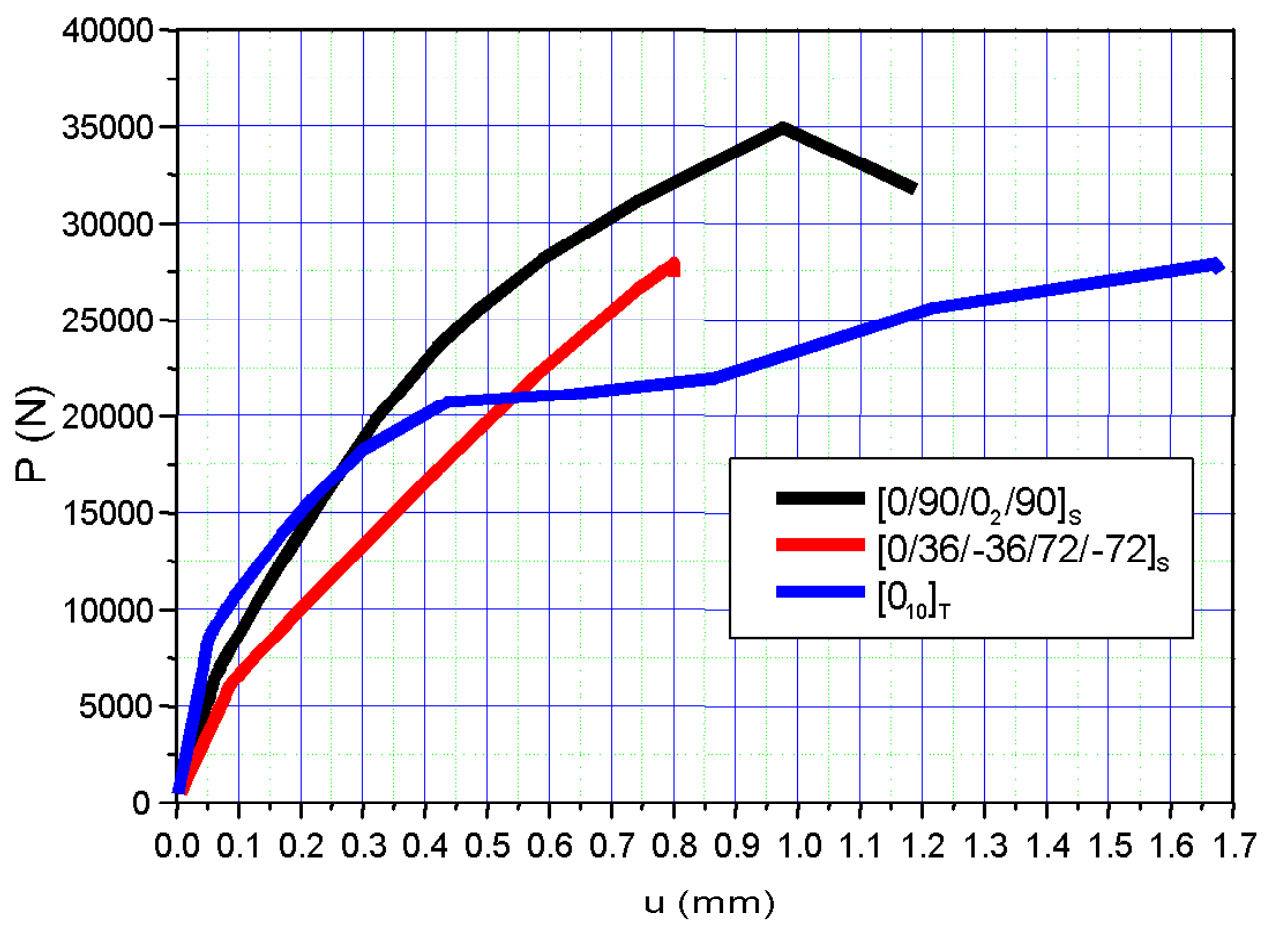

Fig. 3. Load-deflection curves of three different plates of same weight: the optimized plate, a quasiisotropic plate, and a unidirectional plate. 


\section{Optimal Design of Composite Stiffened Panels}

The shape of the stiffened panel, the boundary conditions, and the loading conditions are shown in Fig. 4. The design variables were selected as shown in Table 2. The material properties of the composite material are the same as in Table 1. In order to determine the reference design strength, a composite stiffened panel which has the shape and the stacking sequence as shown in Table 3 was selected and the postbuckling analysis was performed for the reference stiffend panel. As the result of the analysis, the strength of the panel was $65.5 \mathrm{kN}$ and we set the design strength to be a slightly smaller value, $60 \mathrm{kN}$.

Table 2. Definition of design variables of composite stiffened panel design

\begin{tabular}{|c|c|c|}
\hline \multirow{2}{*}{ Skin size } & $\mathrm{L}(\mathrm{mm})$ & 250 \\
\hline & $\mathrm{W}(\mathrm{mm})$ & 160 \\
\hline \multicolumn{2}{|c|}{ Stiffener type } & I \\
\hline \multicolumn{2}{|c|}{ Design failure load, $\mathrm{P}_{\text {fail.design }}(\mathrm{N})$} & 60000 \\
\hline \multirow{3}{*}{ Stiffener Location, s } & $\mathrm{s}_{\min }(\mathrm{mm})$ & 25 \\
\hline & $\mathrm{S}_{\max }(\mathrm{mm})$ & 56 \\
\hline & bits $^{*}$ & 5 \\
\hline \multicolumn{2}{|c|}{ Flange size, f (mm) } & 24 (fixed) \\
\hline \multirow{3}{*}{ Web size, w } & $\mathrm{w}_{\min }(\mathrm{mm})$ & 15 \\
\hline & $\mathrm{W}_{\max }(\mathrm{mm})$ & 78 \\
\hline & bits $^{*}$ & 6 \\
\hline \multirow{3}{*}{ Cap size, c } & $\mathrm{c}_{\min }(\mathrm{mm})$ & 15 \\
\hline & $\mathrm{c}_{\max }(\mathrm{mm})$ & 78 \\
\hline & bits $^{*}$ & 6 \\
\hline \multicolumn{2}{|c|}{ Max. number of the skin plies } & $8 \times 2$ \\
\hline \multicolumn{2}{|c|}{ Max. number of the stiffner plies } & $8 \times 2$ \\
\hline \multicolumn{2}{|c|}{ Bits for a degree } & 3 \\
\hline \multicolumn{2}{|c|}{ Total bits } & 65 \\
\hline \multicolumn{2}{|c|}{ Number of possible designs } & $3.7 \times 10^{19}$ \\
\hline
\end{tabular}

Table 3. Shape and stacking sequence of the reference composite stiffened panel

Stiffener location, Web height, Cap width, Skin stacking Stiffener stacking Ultimate failure Weight, W

\begin{tabular}{ccccccc}
$\mathrm{s}(\mathrm{mm})$ & $w(\mathrm{~mm})$ & $c(\mathrm{~mm})$ & sequence & sequence & load, $\mathrm{P}_{\text {fail }}(\mathrm{N})$ & $\left(\mathrm{mm}^{3}\right)$ \\
\hline \multirow{2}{*}{30} & 25 & 20 & {$[0 / 90 / \pm 45]_{S}$} & {$[0 / 90 / \pm 45]_{S}$} & 65524 & 74500 \\
\hline \hline
\end{tabular}


The optimization result is shown in Table 4 . The strength is $72 \mathrm{kN}$ which is quite larger than the reference design value; however, the weight is smaller than the result of the panel in Table 3. Fig. 4 shows the comparison of the load-deflection curves and the buckling shapes between the reference stiffened panel in Table 3 and the optimized result.

Table 4. Optimal design results of composite stiffened panels

\begin{tabular}{ccccccc}
\hline \hline $\begin{array}{c}\text { Stiffener location, Web height, Cap width, } \\
\mathrm{s}(\mathrm{mm})\end{array}$ & $\mathrm{w}(\mathrm{mm})$ & $\mathrm{c}(\mathrm{mm})$ & sequence & sequence & load, $\mathrm{P}_{\text {fail }}(\mathrm{N})$ & \begin{tabular}{c}
$\left(\mathrm{mm}^{3}\right)$ \\
\hline 52
\end{tabular} \\
\hline
\end{tabular}
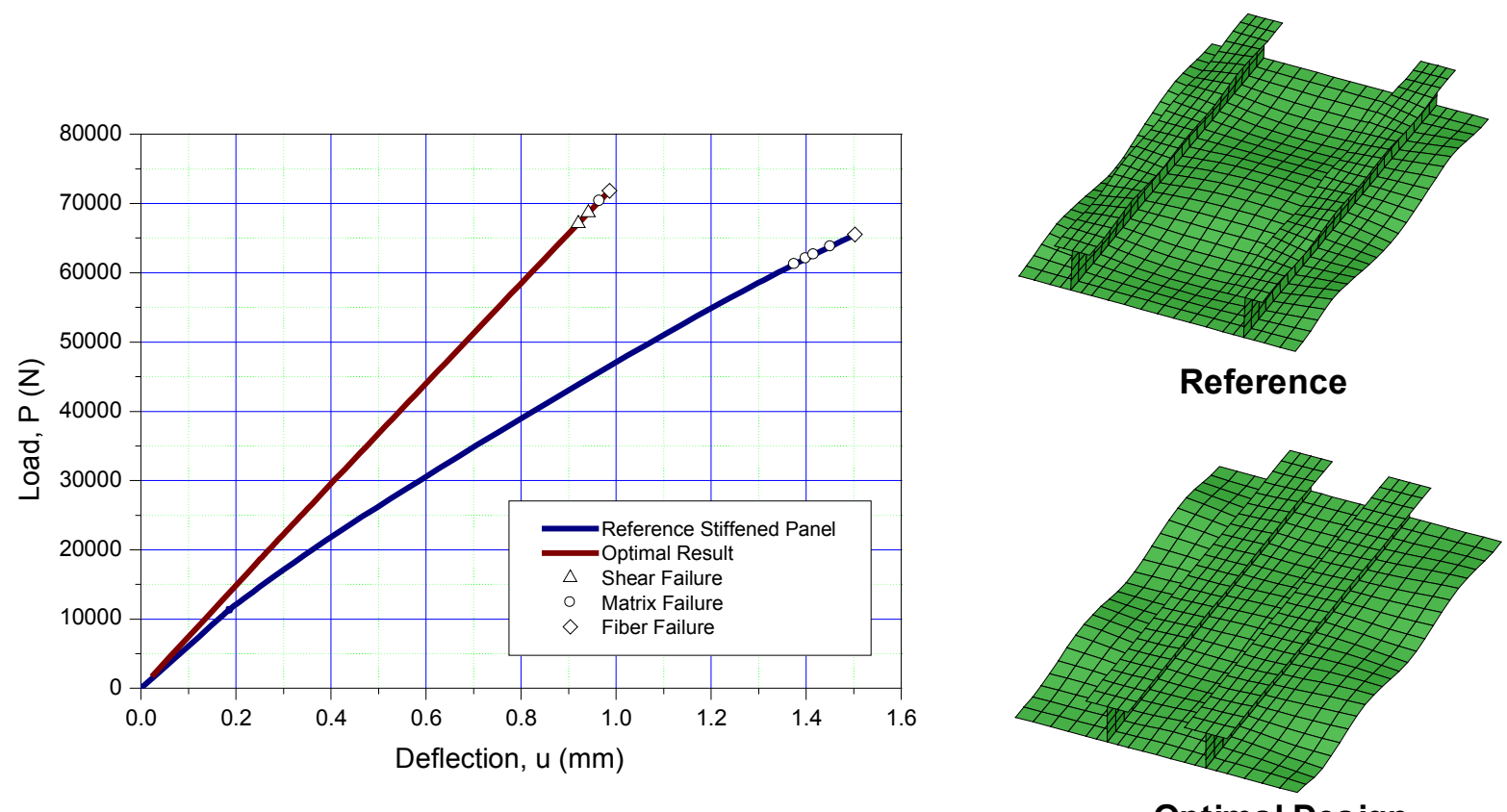

Fig. 4. Comparison of the load-deflection curves and buckling modes between the reference and the optimized result.

\section{CONCLUSION}

In this paper, the weight optimizations of composite structures were studied with considering the postbuckling behavior of composite structures. In order to estimate the postbuckling behavior, a nonlinear finite element analysis code was applied and the modified Genetic Algorithm was used as the optimization method. The optimization was performed for composite plates and stiffened panels and the result showed that the present optimal designs have better performances than conventional designs. 


\section{REFERENCES}

[1] D. K. Shin and Jr. O. H. Griffin, "Minimum-Weight Design of Laminated Composite Plates for Postbuckling Performance," AIAA Paper, presented at the AIAA/ASME/ASCE/AHS 31th structures, Structural Dynamics, and Materials Conference, pp.257-266, 1991.

[2] S. Adali, A. Richter, V. E. Verijenko and E. B. Summers, "Optimal Design of Hybrid Laminates with Discrete Ply Angles for Maximum Buckling Load and Minimum Cost," Composite Structures, Vol.32, pp.409-415, 1995.

[3] B. Malott, R. C. Averill, E. D. Goodman and W. F. Punch, "Use of Genetic Algorithms for Optimal Design of Laminated Composite Sandwich Panels with Bending-Twisting Coupling," AIAA Paper, presented at the AIAA/ASME/ASCE/AHS 36th structures, Structural Dynamics, and Materials Conference, pp.1874-1881, 1996.

[4] A. S. Fine and G. S. Springer, "Design of Composite Laminates for Strength, weight, and Manufacturing," Journal of Composite Materials, Vol.31, No.23, pp.2330-2390, 1997.

[5] C. A. Perry. Z. Gürdal and J. H. Starnes JR, "Minimum-Weight Design of Compressively Loaded Stiffened Panels for Postbuckling Response", Engineering Optimization, Vol.28, pp.175-197, 1997.

[6] J. H. Kweon and C. S. Hong, "An Improved Arc-Length Method for Postbuckling Analysis of Composite Cylindrical Panels," Computers \& Structures, Vol.53, pp.541-549, 1994.

[7] C. W. Kong, I. C. Lee, C. G. Kim, and C. S. Hong, "Postbuckling and failure of stiffened composite panels under axial compression," Composite Structures, Vol.42, pp.13-21, 1998.

[8] C. W. Kong, C. S. Hong, and C. G. Kim, "Postbuckling Strength of Composite Plate with a Hole," Reinforced Plastics and Composites, Vol.20, pp.466-481, 2001.

[9] D. E. Goldberg, Genetic Algorithms in Search, Optimization and Machine Learning, Addison Wesley, Boston, MA, 1989. 